\title{
Analysis and design of hybrid electric regional turboprop aircraft
}

\author{
Mark Voskuijl $^{1}$ (D) Joris van Bogaert ${ }^{1} \cdot$ Arvind G. Rao $^{1}$
}

Received: 10 April 2017/Revised: 22 September 2017 / Accepted: 10 October 2017/Published online: 31 October 2017

(c) The Author(s) 2017. This article is an open access publication

\begin{abstract}
The potential environmental benefits of hybrid electric regional turboprop aircraft in terms of fuel consumption are investigated. Lithium-air batteries are used as energy source in combination with conventional fuel. A validated design and analysis framework is extended with sizing and analysis modules for hybrid electric propulsion system components. In addition, a modified Bréguet range equation, suitable for hybrid electric aircraft, is introduced. The results quantify the limits in range and performance for this type of aircraft as a function of battery technology level. A typical design for 70 passengers with a design range of $1528 \mathrm{~km}$, based on batteries with a specific energy of $1000 \mathrm{Wh} / \mathrm{kg}$, providing $34 \%$ of the shaft power throughout the mission, yields a reduction in emissions by $28 \%$.
\end{abstract}

Keywords Hybrid electric propulsion - Range equation · Aircraft design · Mission analysis

\section{List of symbols}

$C_{\mathrm{L}} \quad$ Lift coefficient [-]

$C_{\mathrm{D}}$ Drag coefficient [-]

$c_{\mathrm{P}}$ Power-specific fuel consumption $\left[\mathrm{m}^{-1}\right]$

$c_{\mathrm{T}} \quad$ Thrust-specific fuel consumption $\left[\mathrm{s}^{-1}\right]$

$E \quad$ Energy [J]

$g$ Gravitational acceleration $\left[\mathrm{m} / \mathrm{s}^{2}\right]$

$H \quad$ Energy per unit fuel or battery $[\mathrm{J} / \mathrm{kg}]$

$p \quad$ Power density $[\mathrm{kW} / \mathrm{kg}]$

$P \quad$ Power $[\mathrm{J} / \mathrm{s}]$

Mark Voskuijl

m.voskuijl@tudelft.nl

1 Delft University of Technology, Kluyverweg 1, 2629 HS Delft, The Netherlands
$P_{\text {a }} \quad$ Power available $[\mathrm{J} / \mathrm{s}]$

$P_{\mathrm{br}} \quad$ Shaft power $[\mathrm{J} / \mathrm{s}]$

$R \quad$ Range [m]

$S \quad$ Power split [-]

$t \quad$ Time [s]

$T$ Thrust $[\mathrm{N}]$

$V \quad$ Airspeed $[\mathrm{m} / \mathrm{s}]$

$W \quad$ Weight $[\mathrm{N}]$

$\eta \quad$ Efficiency [-]

$\Phi \quad$ Supplied power ratio [-]

$\psi \quad$ Hybridization factor [-]

\section{Indices and subscripts}

bat Batteries

cryo Cryocooler

em Electric motor

inv Inverter

prop Propeller

\section{Abbreviation \\ MTOM Maximum take-off mass}

\section{Introduction}

The potential for hybrid electric or even full electric commercial aircraft has received a great deal of attention over the past years. The industry is currently in the process of adopting the 'more-electric' aircraft in which various aircraft systems (pneumatic and hydraulic) are replaced by electric systems [1-5]. Various recent studies highlight the potential of (partly) using electric power for propulsion. This opens a realm of new propulsion system architectures and even new aircraft configurations. Three basic 
approaches to the use of electric power for propulsion can be distinguished.

- Batteries as energy source to (partly) replace fossil fuels.

- Provide electric power at specific flight phases to limit the variation in the gas turbine operability.

- Novel aircraft configurations (e.g., distributed propulsion).

First of all, batteries can be used as an energy source just like conventional fuel. The fundamental challenge in using batteries as an energy source for propulsion is the low specific energy of batteries compared to the high specific energy of conventional jet fuel. The specific energies of state-of-the-art batteries are in the order of $100-200 \mathrm{Wh} / \mathrm{kg}$ at cell level, whereas gasoline has a specific energy of approximately 13,000 Wh/kg. Lithium-air batteries, however, show great promise with a theoretical specific energy of $11,680 \mathrm{Wh} / \mathrm{kg}$ [6]. Many significant challenges have to be overcome before even a small part of this theoretical value can be achieved in reality. Consequentially, the use of batteries as energy source is at the moment only feasible for small aircraft, which have a low weight and limited range. Currently, there are already various flying demonstrators and production versions of manned full electric general aviation aircraft. Several recent small electric aircraft initiatives are described by Wells [7]. A realistic design procedure for small full electric aircraft was recently introduced by Riboldi and Gualdoni [8]. Studies for larger aircraft are usually based on estimates of the specific energy of future batteries. Pornet et al. [9] investigated the use of batteries as energy source alongside conventional jet fuel as a retrofit for short-to-mediumrange single-aisle turbofan aircraft. They conclude that the use of batteries with an energy density of $1500 \mathrm{Wh} / \mathrm{kg}$ as an energy source can provide a large block fuel reduction $(-16 \%)$ on short-range missions in case the energy ratio of fuel and batteries is $82-18 \%$. Further analysis by Pornet et al. demonstrates that batteries with an energy density below $1000 \mathrm{Wh} / \mathrm{kg}$ provide no significant fuel savings at all. A similar study was performed by Friedrich and Robertson [10] in which a Boeing 737-800 was retrofitted with a hybrid electric propulsion system. Assuming a specific energy of $750 \mathrm{Wh} / \mathrm{kg}$, a $10.4 \%$ fuel saving was computed on a $2 \mathrm{~h}$ mission. The energy stored in the batteries is $6 \%$ of the total energy (fuel and batteries). This comes at the expense of an increase in aircraft weight of approximately $10,000 \mathrm{~kg}$. This added weight was, however, not accounted for by a structural redesign of the aircraft. The feasibility of a full electric regional aircraft concept designated VOLTAIR was investigated by Stückl et al. [11]. Their calculations demonstrate that it is feasible to design a full electric regional aircraft for 70 passengers with a design range of $1667 \mathrm{~km}$ if batteries with a specific energy of $750 \mathrm{Wh} / \mathrm{kg}$ are available. The VOLTAIR design, however, is also based on the beneficial effects of other technologies; (1) a propulsive fuselage configuration featuring boundary layer ingestion, (2) a low slenderness fuselage with reduced structural weight and (3) a $60 \%$ natural laminar flow wing. These combined technologies are claimed to yield a $25 \%$ improvement in energy efficiency. The VOLTAIR aircraft design does not converge for longer range missions or larger payloads, indicating a physical limit in size for full electric regional aircraft. The studies described above highlight that there is a limit in aircraft size even when significant improvements in battery technology are achieved. The use of batteries as energy source alongside conventional fuel therefore shows the most promise for the regional aircraft segment. Furthermore, the vast majority of air travel is conducted by regional aircraft and short-to-medium-range single-aisle jets [12]. At present, however, there are no research studies on the use of batteries as energy source for regional turboprop aircraft with a conventional configuration. A summary of current and future battery technology at both cell and system level is shown in Fig. 1.

A second approach to the use of batteries for propulsion is to provide additional power in specific mission phases such as take-off and climb. By doing so, the conventional gas turbines can be optimized for a single flight condition (cruise). As a result, they can be smaller (lower weight) and more efficient. It was demonstrated by Perullo and Mavris [13] that it is important to combine the mission optimization, aimed at finding the optimum transient power split, with the aircraft design optimization. Ang et al. [14] investigated the benefits of this approach for a hybrid electric version of an Airbus A320. It is demonstrated that for short-range missions of $1000 \mathrm{~km}$ a fuel burn saving of $7.5 \%$ can be achieved when the engine is scaled to $90 \%$

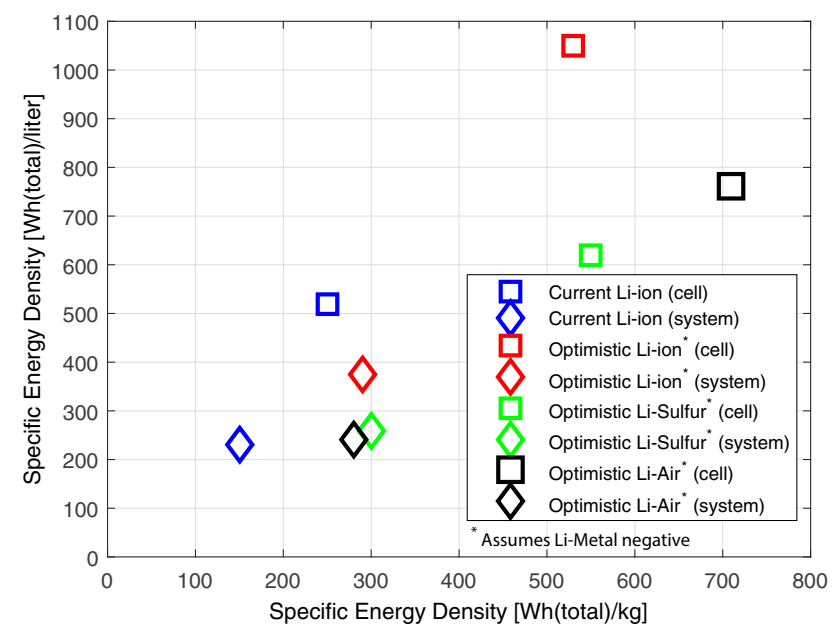

Fig. 1 High energy batteries cell and system level comparison 
and electric power is used to assist the take-off and climb phases (with 25 and $14 \%$ electric power, respectively). These estimates were based on batteries with a specific energy of $600 \mathrm{Wh} / \mathrm{kg}$.

Finally, having a hybrid electric propulsion system makes it possible to separate the engine from the propulsor and thereby new aircraft configurations become feasible. An example is the NASA N3-X design of a hybrid wing body aircraft with a turboelectric distributed propulsion system [15]. Distributed propulsion can be used to enhance the efficiency by wake-filling and boundary layer ingestion. In addition, a higher integration of the propulsion system and airframe can lead to a lower structural weight. Furthermore, in case a single core engine is used to power multiple electrically driven fans, a higher effective bypass ratio can be achieved [16]. This is applied for example in the Airbus-Rolls Royce E-Thrust concept [17].

It should be noted that the three main approaches to the use of hybrid electric propulsion described above are complementary and can be combined. The main objective of this research study is to investigate the potential fuel burn savings specifically for regional turboprop aircraft with a conventional configuration in case the energy source is a combination of conventional fuel and batteries. The identification of the optimal ratio of gas turbine power and electric power throughout the mission is included in the design study. A key element in the analysis of hybrid electric regional aircraft is therefore an accurate mission analysis. For the first initial design iterations, an analytical approach to mission analysis is used. The traditional Bréguet range equation is, however, not suitable for hybrid electric aircraft which use batteries as an energy source. The second objective of this study is therefore to introduce a new range equation, suitable for hybrid electric aircraft within the context of the flying strategies and design framework used. Alternative formulations of (hybrid) electric range equations can be found in references $[18,19]$. For subsequent design iterations, detailed flight path simulations are used. Ideally, the objective of the design optimization should be to minimize emissions or direct operating costs in relation to emissions. Practically, it is difficult to design for costs as these depend on the economic situation. In conventional aircraft design, the maximum take-off mass is therefore often chosen as objective. This is not a feasible option in the current study since the battery weight is very high. Therefore, fuel burn is chosen as optimization target. It should be noted that the environmental benefit of hybrid electric regional turboprop aircraft as described in this paper is only achieved when the energy stored in the batteries is created by renewable energy sources. The source of energy for the batteries is considered to be out of the scope of the current study.
The structure of this paper is as follows. First, an existing regional turboprop aircraft will be selected as a reference. Next, a hybrid electric propulsion system architecture will be defined for this aircraft. This includes a description of the hybrid electric propulsion system parameters. The overall design methodology will be discussed subsequently. For validation purposes, this design method will first be used to design a conventional turboprop aircraft with the same top-level aircraft requirements as the reference aircraft. After validation, the design method will be used to explore the design space ranging from $100 \%$ conventional fuel to full electric propulsion. This will be done for various design ranges and battery technology levels. A single hybrid electric aircraft design which shows most promise in terms of fuel savings and practical feasibility will finally be selected and investigated in more detail. Finally, conclusions and recommendations are made.

\section{Hybrid electric regional aircraft architecture}

\subsection{Reference aircraft}

The ATR-72-600 is selected as reference aircraft. At present, more than 800 aircraft have been produced. It is a stretched version of the ATR-42 and the standard configuration can transport 70 passengers over a design range of $1528 \mathrm{~km}$. The maximum cruise speed is $510 \mathrm{kts}$ (true airspeed) and the maximum operating altitude equals $7600 \mathrm{~m}$. It features two Pratt and Whitney PW 127 M engines, each delivering 2500 maximum continuous shaft horsepower. The propellers have six blades and a diameter of $3.93 \mathrm{~m}$.

\subsection{Hybrid electric propulsion system architecture}

Various distinct hybrid electric propulsion system architectures are possible [20]. The most commonly used are the series hybrid architecture and the parallel hybrid architecture. For road vehicle applications, the series hybrid architecture has the lowest fuel consumption [21]. However, it has a larger weight than a parallel architecture, which is especially important in aerospace applications [22]. In a design study by Friedrich and Robinson, which was limited to light aircraft, it was demonstrated that the parallel configuration provides the highest efficiency for aerospace applications [23]. For the aforementioned reasons, the parallel configuration is selected as solution for hybrid electric regional aircraft. A schematic representation of the system is provided in Fig. 2. Fuel is used to power a turboshaft engine, and batteries are used to power an electric motor. Both turboshaft engine and electric motor power the drive train coupled to the propellers. 


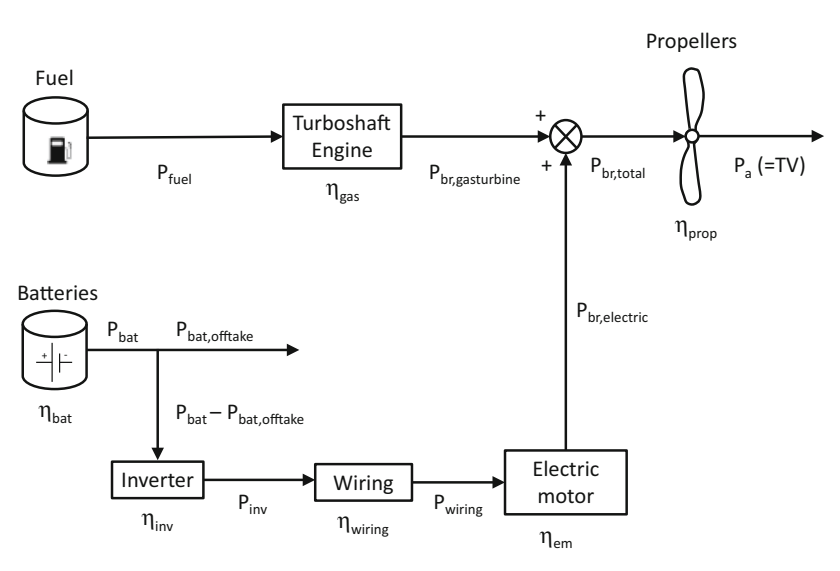

Fig. 2 Parallel hybrid electric propulsion system architecture

It is essential to have accurate data representing the weight and efficiency of all elements in the propulsion system. Because lithium-air batteries have by far the largest theoretical specific energy [6], this type is chosen for the aircraft design. Design studies will be conducted for a range in battery-specific energy of 750-1500 Wh/ $\mathrm{kg}$. The lower boundary of $750 \mathrm{Wh} / \mathrm{kg}$ is chosen because various studies have indicated that this value is needed at least for hybrid electric aircraft to be a realistic option $[8,24]$. With present lithium-air batteries (the best reported laboratory cell has a specific energy of $363 \mathrm{Wh} /$ $\mathrm{kg}$ [25]), this is by far not possible and it is estimated that batteries with an energy density of $750 \mathrm{Wh} / \mathrm{kg}$ will most likely not be available before the year 2035 [26]. A notable feature of these batteries is that they slightly increase in weight during operation [6]. For the cell voltages, it is assumed that they have a high voltage in the order of $10 \mathrm{kV}$ in order to minimize transmission losses. Current intensities of 50-100 A are envisioned. Note that the cell voltage and current intensity does not affect the design process reported in this research study. The main parameters of the hybrid electric propulsion system are summarized in Table 1.
The electric motor power density is a conservative estimate based upon predictions reported in references [28-30]. According to NASA, a cryocooler is expected to have a power requirement of $0.16 \%$ of the maximum rated power output of the electric motor [29]. However, a more conservative value of $0.45 \%$ is chosen. The power density of the cryocooler is based on the work by Ashcraft et al. [29]. Since high-temperature superconducting motors require AC power, an inverter is needed [30]. Aluminum cables with a high voltage $(6 \mathrm{kV})$ are used for the wiring. This relative high voltage is needed to reduce the cable diameter. Furthermore, aluminum cables have a lower weight than copper cables for the same voltage and current. The weight estimation is a function of current for a cable rated at $6 \mathrm{kV}$ and is based on commercial off the shelf products presently available [31]. An impression of the location of the hybrid electric propulsion system components in the aircraft is presented in Fig. 3.

\section{Design methodology}

For the design and analysis of the hybrid electric regional aircraft, a software framework designated as initiator, is used [32]. This framework is a design and analysis method suitable for both conventional and unconventional aircraft. It is based on a combination of physics-based analyses and empirical methods. This method has been verified in earlier studies for various turbofan aircraft. For the purpose of the current work, the method has been first extended with sizing modules for turboprop engines. The sizing of the gas turbine and propeller is based on well-established empirical relations [33, 34]. Realistic variations of fuel flow and maximum power with altitude and airspeed are included in the propulsion system analysis. An introduction to turboprop generalized performance can be found in [35]. An alternative design and sizing approach for hybrid electric aircraft is reported in [36]. As a first step after
Table 1 Hybrid electric propulsion system parameters

\begin{tabular}{lll}
\hline Parameter & Value & Source \\
\hline Lithium-air battery-specific energy range $[\mathrm{Wh} / \mathrm{kg}]$ & $750-1500$ & Design choice \\
Lithium-air battery mass variation $[\mathrm{kg} / \mathrm{Wh}]$ & 0.000192 & {$[6]$} \\
Efficiency batteries $\eta_{\text {bat }}[-]$ & 0.95 & \\
Efficiency electric motor $\left(\right.$ excluding cryocooler), $\eta_{\mathrm{em}}[-]$ & 0.98 & {$[27]$} \\
Efficiency inverter $\eta_{\text {inv }}[-]$ & 0.98 & {$[28]$} \\
Efficiency wiring, $\eta_{\text {wiring }}[-]$ & 0.99 & \\
Power density electric motor, $p_{\mathrm{em}}[\mathrm{kW} / \mathrm{kg}]$ & 15 & {$[29,30]$} \\
Power density inverter, $p_{\text {inv }}[\mathrm{kW} / \mathrm{kg}]$ & 20 & {$[28]$} \\
Power density cryocooler, $p_{\text {cryo }}[\mathrm{kW} / \mathrm{kg}]$ & 0.33 & {$[29]$} \\
Cryocooler power requirement $[\%$ of max. electric motor power output] & 0.45 & {$[29]$} \\
$U_{\text {cable }}$ & $6 \mathrm{kV}$ & Design choice \\
\hline
\end{tabular}


implementation of the new sizing modules, the design and analysis method is applied to the design of a reference aircraft which has the same top-level aircraft requirements as the ATR-72-600. Results are presented in Table 2 and a

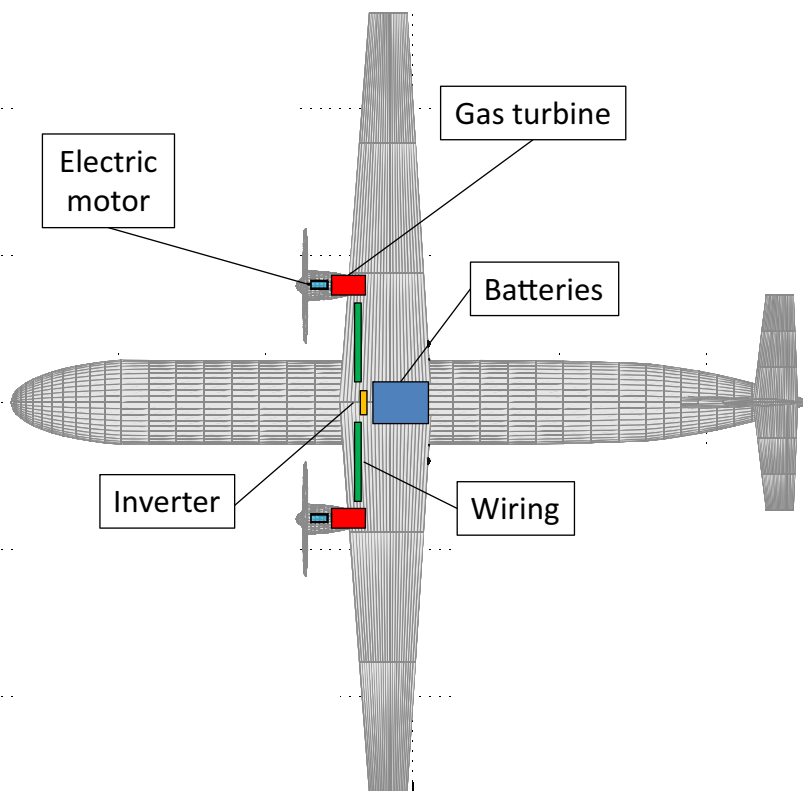

Fig. 3 Aircraft hybrid electric propulsion integration comparison of the planform of the actual ATR-72-600 and the reference design is displayed in Fig. 4. Differences between the design and the real aircraft are typically in the order of $2 \%$. This is deemed very accurate for a conceptual design framework.

Next, the design framework is extended with sizing modules for the electric components and a new mission analysis. Various approaches to quantify the level of hybridization can be found in the literature. Two are used in this study; the degree of hybridization at; (1) the source and (2) at the shaft driving the propeller. Both approaches have advantages and disadvantages and they are therefore used side by side. The power split $(S)$ is defined as the ratio of shaft power provided by the electric motor and gas turbine, whereas the hybridization factor $(\psi)$ is defined as the ratio of the energy stored in the batteries and total energy stored in fuel and batteries.

$S=\frac{P_{\text {br,electric }}}{P_{\text {br,total }}}$

$\psi=\frac{E_{\text {bat }}}{E_{\text {total }}}$

The power split can, in fact, vary throughout the mission and for this reason, another parameter is introduced: the supplied power ratio. This is the defined as the total electric

Table 2 Comparison ATR-72600 and reference aircraft design

\begin{tabular}{lllc}
\hline Parameter & ATR-72-600 & Reference aircraft design & Difference (\%) \\
\hline MTOM (kg) & 22,800 & 22,340 & -2.0 \\
Mission fuel mass $(\mathrm{kg})$ & 2000 & 2050 & +2.5 \\
Empty mass $(\mathrm{kg})$ & 13,010 & 12,780 & -1.8 \\
Wing span $(\mathrm{m})$ & 27.05 & 26.5 & -2.0 \\
Wing area $\left(\mathrm{m}^{2}\right)$ & 61 & 58.54 & -4.5 \\
Fuselage length $(\mathrm{m})$ & 27.17 & 27 & -0.6 \\
\hline
\end{tabular}
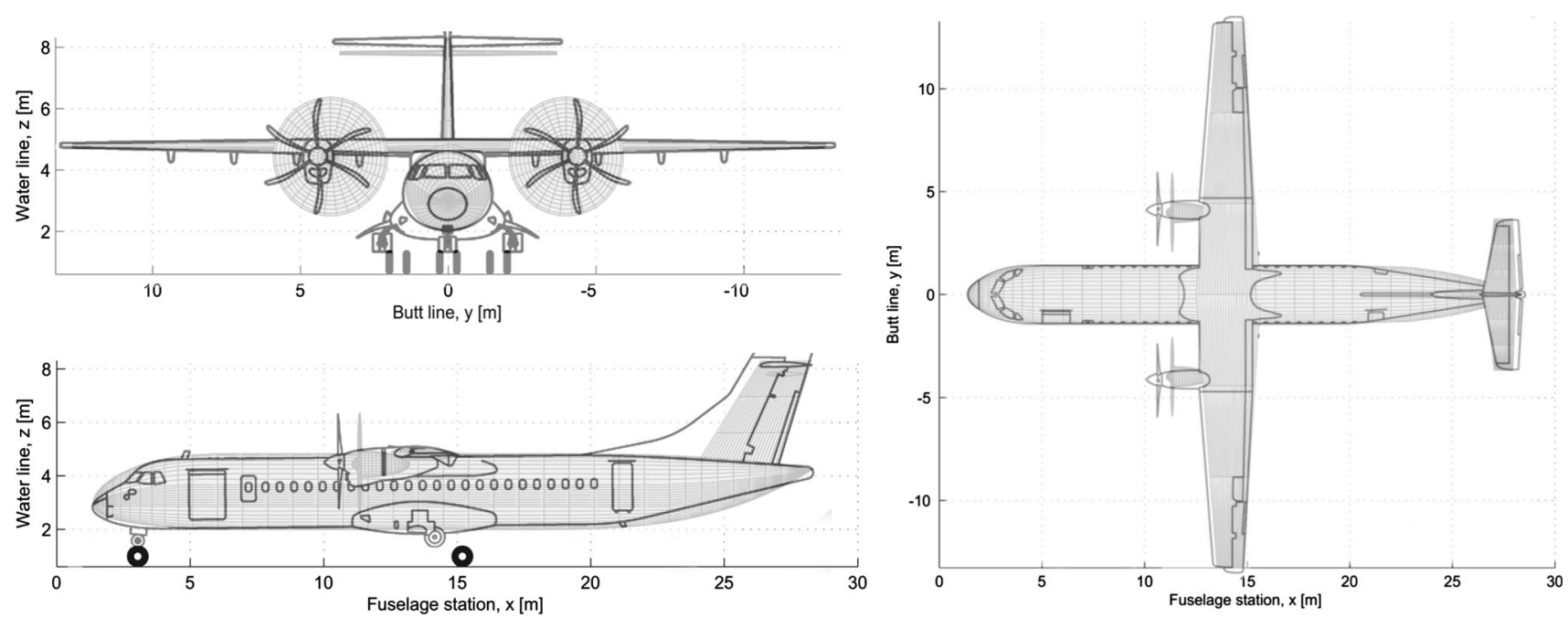

Fig. 4 Comparison ATR-72-600 and reference aircraft design planform 
motor power integrated over the mission in relation to the total shaft power integrated over the mission.

$\Phi=\frac{\int P_{\text {br,electric }}}{\int P_{\text {br }, \text { total }}}$

For all definitions, a value of zero represents a conventional aircraft and a value of 1 represents a full electric aircraft. Using the first two definitions, an analytical hybrid electric range equation can be derived (see Appendix).

$$
\begin{aligned}
R_{\text {hybrid }} & =\frac{\eta_{\text {prop }}}{g\left(c_{\mathrm{P}} \frac{H_{\text {fuel }}}{g}(1-S)+\frac{S}{\eta_{\text {elec }}}\right)} \frac{C_{\mathrm{L}}}{C_{\mathrm{D}}} \frac{H_{\text {bat }} H_{\text {fuel }}}{\left(\psi H_{\text {fuel }}+(1-\psi) H_{\text {bat }}\right)} \\
& \ln \left(\frac{\frac{\left(\psi H_{\text {fuel }}+(1-\psi) H_{\text {bat }}\right)}{H_{\text {bat }} H_{\text {fuel }}} g E_{\text {start }}+W_{\text {empty }}+W_{\text {payload }}}{W_{\text {empty }}+W_{\text {payload }}}\right)
\end{aligned}
$$

Note that this equation reduces to the traditional Bréguet range equation in case the power split and hybridization factor are set to zero. Furthermore, since the final energy is zero at the end of the cruise flight (in case only the cruise flight segment is considered and no reserve fuel or energy is taken into account), the power split and hybridization factor are directly related to each other. For a full electric aircraft, the power split and hybridization factor are both 1 . In these scenarios, the range equation becomes:

Conventional $(S=\psi=0)$ :

$$
R=\frac{\eta_{\text {prop }}}{c_{\mathrm{P}}} \frac{C_{\mathrm{L}}}{C_{\mathrm{D}}} \ln \left(\frac{W_{\text {fuel }}+W_{\text {empty }}+W_{\text {payload }}}{W_{\text {empty }}+W_{\text {payload }}}\right)
$$

Full electric $(S=\psi=1)$ :

$$
R=\eta_{\text {elec }} \frac{H_{\text {bat }}}{g} \eta_{\text {prop }} \frac{C_{\mathrm{L}}}{C_{\mathrm{D}}} \ln \left(\frac{W_{\text {bat }}+W_{\text {empty }}+W_{\text {payload }}}{W_{\text {empty }}+W_{\text {payload }}}\right) .
$$

Alternative analytical formulations of range for (hybrid) electric aircraft can be found in [18, 19]. The analytical range equation presented above is used for the first design iterations. For later design iterations, a more accurate mission analysis is conducted based on numerical flight path simulations. In that case, it is possible to vary and optimize the power split throughout the mission in order to obtain minimum emissions. In the present work, two strategies are investigated:

- Constant power split.

- Constant operating mode of gas turbine.

In the first strategy, the ratio of the power setting (throttle) of the gas turbine and the electric motor is fixed. In the second strategy, the input to the gas turbine is predefined and this engine runs at its most efficient point during the majority of the mission. The rest of the power is delivered by the electric motor. An example mission simulation with the constant power split strategy is presented in Fig. 5. Strictly speaking, there is only a constant split between the throttle setting of the electric motor and the gas turbine. The power delivered by the gas turbine, however, depends on the flight altitude (air density and altitude) and therefore shows variations during climb and descent, which are not present for the power delivered by the electric motor. The electric motor throttle could have been varied simultaneously in order to achieve a constant power split at the shaft instead of a constant split in throttle setting. Practically, the approach of having a constant throttle split is more straightforward to implement in the automatic control laws of an aircraft. Furthermore, this approach results in a slightly improved climb performance. Furthermore, it should be noted that the mission simulation includes both the take-off and landing phases. However, since the distance covered in take-off and landing is small compared to the other mission phases, this is not represented in Fig. 5. The required take-off power is based on the power loading diagram traditionally used conceptual/ preliminary aircraft design studies. The power setting is maximum during take-off and the power split is taken into account. Important parameters such as the addition of landing gear drag and friction of the tires are also included in the take-off and landing simulation. It is assumed that the batteries can deal with the power peak requested during take-off which results in a high current intensity. This is can be a rather crude assumption for the constant operating mode strategy.

For all aircraft designs evaluated in this research study, the operating mode has only a very small effect on the final result in terms of MTOM and fuel consumption. This justifies to a certain extent the assumption that the power peak can be delivered by the batteries. It is a recommendation for future research to investigate the effect of this assumption this further. For sake of brevity, all results presented in the next section are therefore based on a single operating mode (the constant power split). It is recommended for future research to perform a true mission optimization in which electric motor power, gas turbine power airspeed and altitude are varied throughout the flight in order to minimize emissions subject to realistic operating constraints. An example of such an optimization study is reported by Perullo and Mavris [13]. Such a study is more feasible for a single or limited number of designs. In the current study, this is not feasible since a large design space is explored and each single converged design requires a significant computational effort as all disciplines are involved. 
Fig. 5 Mission simulation example for mission range of $1528 \mathrm{~km}$ with extended range for diversion to alternate airport (take-off and landing are included but not visible)

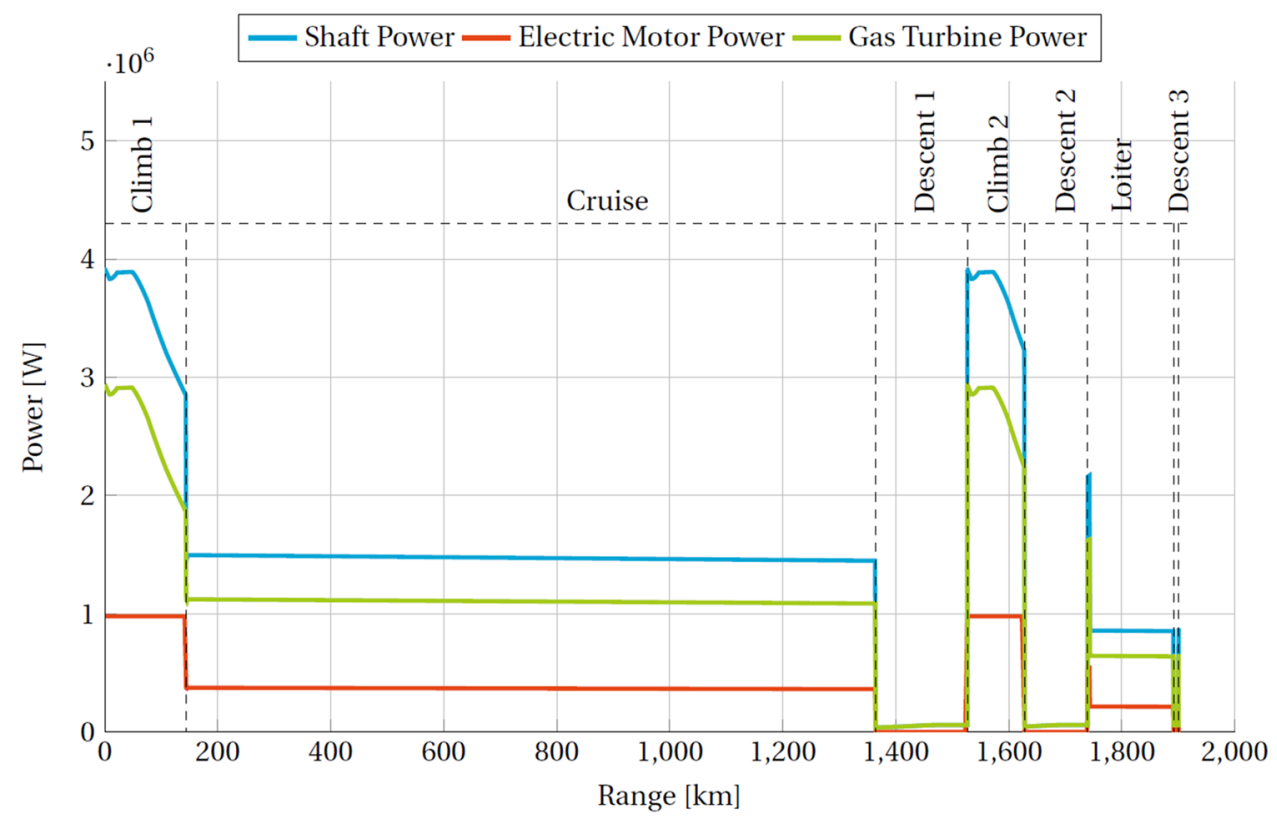

\section{Results and discussion}

The effect of the power split and the specific energy of the batteries on the fuel mass, battery mass and total aircraft mass is investigated using the design framework. Results are presented in Figs. 6 and 7.

The battery mass increases significantly with a higher power split and fuel mass decreases as expected from Eq. 3. The trend lines in Figs. 6 stop when the design does not converge anymore, indicating a hard limit to the design space based on battery technology level. The complete aircraft design is modified when the weight (and volume) of components in the propulsion system change due to the well-known snowball effect. The maximum take-off mass for various power splits and battery technology levels is visualized in Fig. 8. The mass of the hybrid electric power train components, excluding the energy source (batteries and fuel) and the propellers, is represented in Fig. 9. Compared to the masses of the energy sources, the electric components in the power train also have a significant effect on the overall mass. The ratio of the masses of the combined power train systems over the weight of the energy sources, however, decreases. In all scenarios, the total mass of the hybrid electric power train is larger than the mass of two conventional gas turbines.

In all the results presented so far, the design range was fixed to $1528 \mathrm{~km}$. The benefits of a hybrid electric propulsion system are also explored for various design ranges and power splits. This is done assuming the availability of batteries with a specific energy of $1000 \mathrm{Wh} / \mathrm{kg}$. Results are presented in Fig. 10. In this figure, the feasible design limit is highlighted. This demonstrates that it is
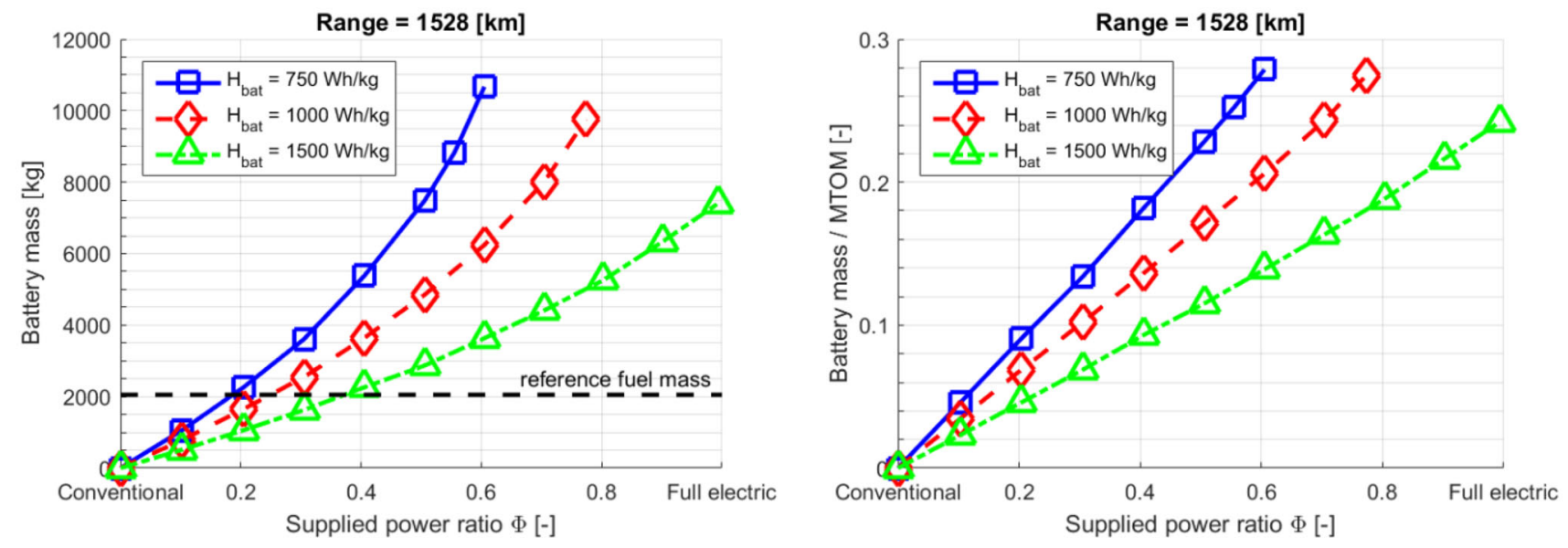

Fig. 6 Battery mass (left) and ratio of battery mass and MTOM as a function of supplied power ratio 

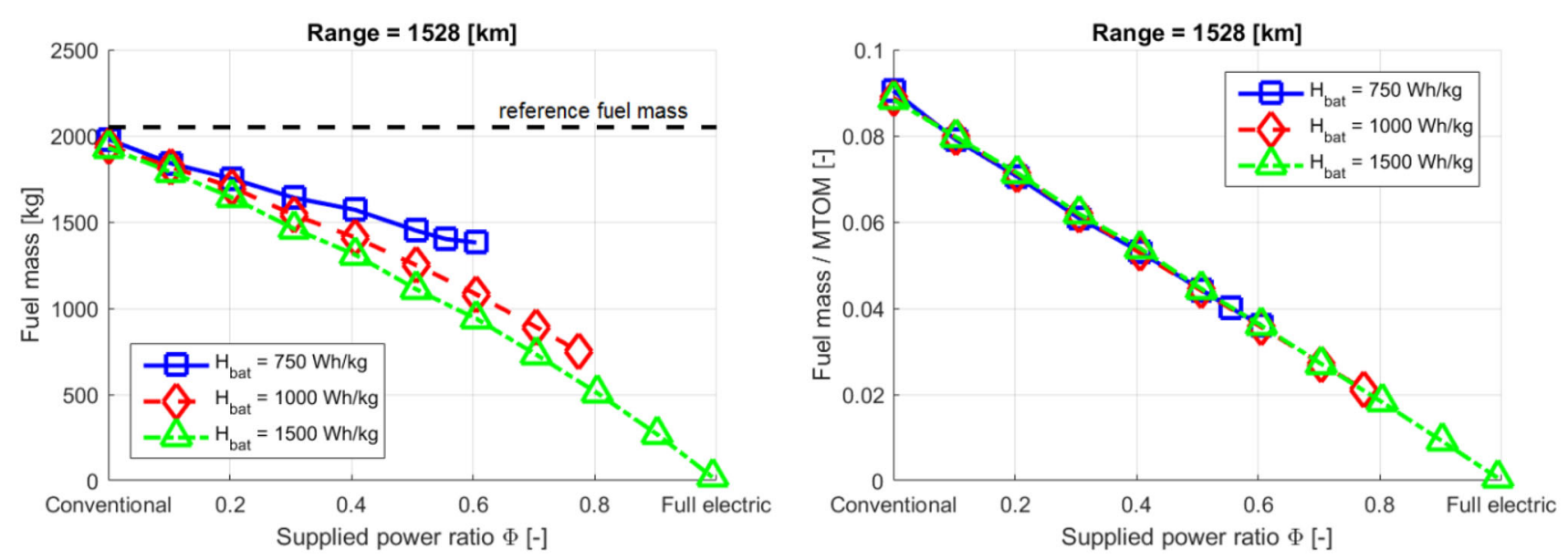

Fig. 7 Fuel mass (left) and ratio of fuel mass and MTOM as a function of supplied power ratio

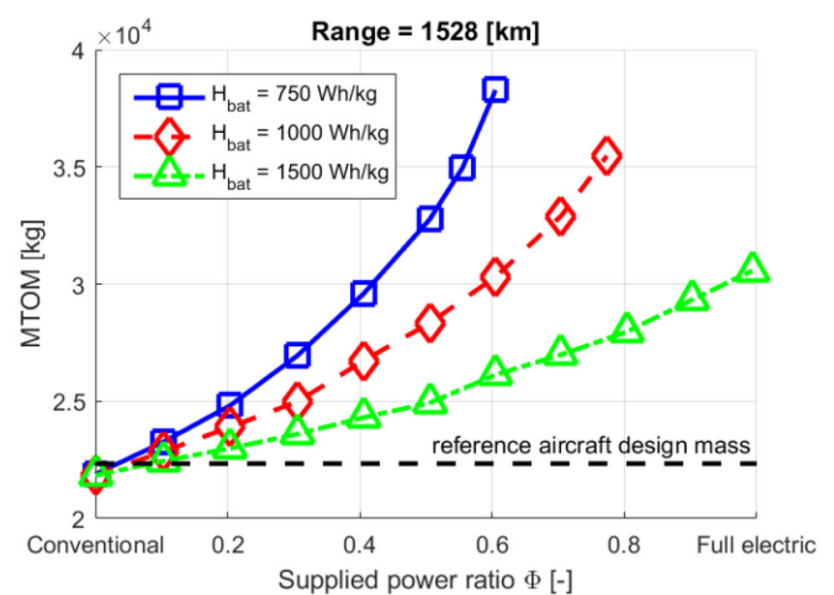

Fig. 8 MTOM as a function of supplied power ratio

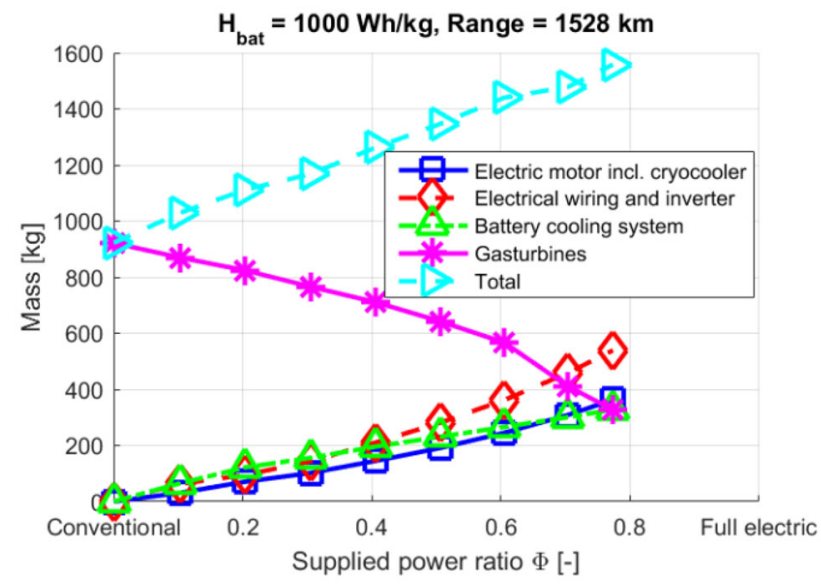

Fig. 9 Mass of hybrid electric power train components

beneficial to use a hybrid electric architecture for shortrange missions. For comparison, the ATR-72-600 is also represented.

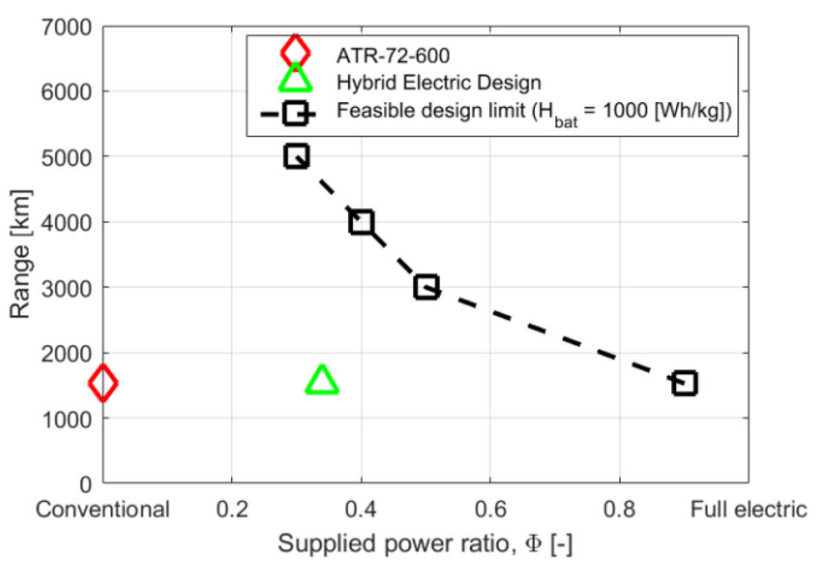

Fig. 10 Feasible design space hybrid electric regional aircraft

The analyses above showed general trends and gave an overview of the whole design space. To get more insight, one specific hybrid electric design is selected to evaluate in more detail. A design with a supplied power ratio of 0.34 , a range of $1528 \mathrm{~km}$ and a battery-specific energy of $1000 \mathrm{Wh} / \mathrm{kg}$ is chosen for a number of reasons. First of all, higher benefits are obtained for short-range missions and this particular range makes a clear comparison with the ATR-72-600 possible. Second, as all the analyses are based on relatively low fidelity methods, the chosen design should have a safe margin from the design limit. Third, many aspects besides the environmental benefits affect the feasibility of a design. Just to name one, the MTOM will affect the production cost of an aircraft. Thus, a low power split is representative of designs which are more feasible. On the other hand, a high power split is beneficial in terms of emissions. In order to balance these conflicting requirements, a supplied power ratio of 0.34 is chosen. A comparison between the selected design and the reference design (similar to the ATR-72-600) is presented in Table 3. 
Table 3 Comparison reference and selected hybrid electric aircraft design $(\Phi=0.34)$

\begin{tabular}{llll}
\hline Parameter & Reference aircraft & Hybrid electric aircraft & Difference \\
\hline MTOM $(\mathrm{kg})$ & 22,340 & 25,470 & $+14 \%$ \\
Mission fuel mass $(\mathrm{kg})$ & 2050 & 1470 & $-28 \%$ \\
Battery mass $(\mathrm{kg})$ & 0 & 2948 & $\mathrm{n} / \mathrm{a}$ \\
Battery energy density $(\mathrm{Wh} / \mathrm{kg})$ & $\mathrm{n} / \mathrm{a}$ & 1000 & $\mathrm{n} / \mathrm{a}$ \\
Empty mass $(\mathrm{kg})$ & 12,780 & 13,552 & $+6 \%$ \\
Total energy stored in batteries and fuel $(\mathrm{MWh})$ & 26.19 & 21.73 & $-17 \%$ \\
Wing span $(\mathrm{m})$ & 26.5 & 28.8 & $+8.7 \%$ \\
Wing area $\left(\mathrm{m}^{2}\right)$ & 58.54 & 69.1 & $+18 \%$ \\
Fuselage length & 27 & 27 & $0 \%$ \\
\hline
\end{tabular}

The total mission fuel needed is reduced by $28 \%$. This comes at the expense of a larger aircraft in terms of MTOM $(+14 \%)$ and wing area. The fuselage, however, is nearly identical since it holds the same number of passengers. From this it can be concluded that there is definitely the possibility of drastic fuel weight reduction by using the hybrid electric aircraft concept (up to about $30 \%$ power split), provided that there is sufficient technological progress, particularly pertaining to battery-specific energy density. Although outside of the scope of this research study, it should be noted that the energy in the batteries is generated at some point. This should be done using renewable energy sources. Otherwise, the fuel benefits on aircraft level are diminished. Furthermore, the batteries are not recharged in flight and should therefore be replaced quickly on airports. This operational process could have a significant impact on the turn around time of the aircraft should be investigated further.

\section{Conclusions and recommendations}

The potential environmental benefits of a hybrid electric propulsion system for regional turboprop aircraft are investigated. Lithium-air batteries are used as primary energy source alongside conventional fuel in a parallel hybrid electric propulsion system architecture. A largely physics-based analysis and design tool is used to explore the design space, assuming a future battery technology level with specific energies ranging from 750 to $1500 \mathrm{Wh} /$ $\mathrm{kg}$. The tool is validated for conventional turboprop aircraft. The feasible design space in terms of mission range and level of hybridization is quantified. The high weight of batteries compared to fuel has a large effect on the designs. Other systems such as battery cooling, wiring have a significant impact on the overall aircraft weight and should, therefore, be taken into account as well. Furthermore, it is essential to tightly couple an accurate mission analysis with the aircraft design procedure. A new range equation suitable for hybrid electric aircraft is introduced. Results demonstrate that hybrid electric propulsion can provide a significant reduction in emissions for turboprop aircraft designed for short-range missions $(1528 \mathrm{~km})$. A typical design which has $34 \%$ electric shaft power requires $28 \%$ less mission fuel at the expense of a larger aircraft in terms of weight and wing area. An additional benefits of this configuration which were not quantified in the current research, are a reduction in local emissions at the airport and a noise reduction during take-off and landing.

It is recommended to further investigate the operational consequences of operating regional aircraft with large battery packs on airports. Another recommendation is to perform detailed mission optimization studies to determine optimal flying strategies for hybrid electric regional aircraft. Furthermore, the safety of such an aircraft is of paramount importance and consequences for the certification process should be investigated. Finally, the results rely on significant improvements in battery technology. It is therefore essential to tackle the associated challenges in battery development.

Open Access This article is distributed under the terms of the Creative Commons Attribution 4.0 International License (http://crea tivecommons.org/licenses/by/4.0/), which permits unrestricted use, distribution, and reproduction in any medium, provided you give appropriate credit to the original author(s) and the source, provide a link to the Creative Commons license, and indicate if changes were made.

\section{Appendix}

The range of a conventional fuel powered aircraft (zero wind conditions, thrust vector parallel to the airspeed vector) can be computed based on the Bréguet range equation.

$R=\int_{W_{\text {final }}}^{W_{\text {start }}} \frac{V}{c_{\mathrm{T}}} \frac{C_{\mathrm{L}}}{C_{\mathrm{D}}} \frac{1}{W} \mathrm{~d} W$ 
The solution to the integral depends on the flying strategy used (e.g., gradual climb at constant airspeed and angle of attack) and the models used to represent the propulsion system and the aerodynamic characteristics. Solutions to the most common flying strategies can be found in many standard text books on aircraft performance. The range equation is based on the fact that weight gradually changes throughout the flight, hence the integration over the aircraft weight. Therefore, the range equation cannot be applied to aircraft which (partly) use batteries as energy supply. Fundamentally, the range can be determined by integrating speed over time.

$R=\int_{t_{\text {start }}}^{t_{\text {final }}} V \mathrm{~d} t$

The energy stored in batteries and fuel can be related to the time to solve this. As time progresses, the energy stored in the batteries or as fuel reduces. The power (energy per second) used is the summation of battery power and fuel power.

$\frac{\mathrm{d} E}{\mathrm{~d} t}=\frac{\mathrm{d} E_{\text {fuel }}}{\mathrm{d} t}+\frac{\mathrm{d} E_{\mathrm{bat}}}{\mathrm{d} t}$

The time rate of change of the energy stored in the fuel can be related to the fuel flow and the energy density of the fuel. Furthermore, the shaft power delivered by the turboshaft engine is related to the fuel flow through the power-specific fuel consumption.

$F=-\frac{\mathrm{d} W_{\text {fuel }}}{\mathrm{d} t}=-\frac{g}{H_{\text {fuel }}} \frac{\mathrm{d} E_{\text {fuel }}}{\mathrm{d} t}$

$F=c_{\mathrm{P}} P_{\text {br,gasturbine }}$

The power split defines the relation of the shaft power delivered by the turboshaft engine to the total shaft power delivered to the propeller. The efficiency of the propeller determines how much of the shaft power is transformed into power available.

$P_{\mathrm{br}, \text { gasturbine }}=(1-S) P_{\mathrm{br}, \mathrm{total}}=(1-S) \frac{P_{\mathrm{a}}}{\eta_{\text {prop }}}$

Thus, the change of energy stored by means of fuel can be expressed as a function of power available.

$\frac{\mathrm{d} E_{\text {fuel }}}{\mathrm{d} t}=-\frac{c E}{\eta_{\text {prop }}} \frac{H_{\text {fuel }}}{g}(1-S) P_{\mathrm{a}}$

Along the same lines, the energy stored in the batteries can be expressed in terms of the power available.

$\frac{\mathrm{d} E_{\text {bat }}}{\mathrm{d} t}=-\frac{P_{\text {brelectric }}}{\eta_{\text {elec }}}=-\frac{S}{\eta_{\text {elec }} \eta_{\text {prop }}} P_{\text {a }}$

By combining Eqs. 13 and 14, an equation for the change of total energy with time is obtained. $\frac{\mathrm{d} E}{\mathrm{~d} t}=-\left(\frac{c_{\mathrm{P}}}{\eta_{\text {prop }}} \frac{H_{\text {fuel }}}{g}(1-S)+\frac{S}{\eta_{\text {elec }} \eta_{\text {prop }}}\right) P_{\mathrm{a}}$

In quasi-steady, quasi-rectilinear flight, thrust must equal drag and lift equals weight. Assuming the thrust vector is parallel to the airspeed vector, Eq. 16 can be determined.

$P_{\mathrm{a}}=D V=\frac{C_{\mathrm{D}}}{C_{\mathrm{L}}} W V$

Now the basic range equation for hybrid electric cruise flight can be created by combining Eqs. 8, 15 and 16.

$R=\int_{E_{\text {final }}}^{E_{\text {start }}} \frac{1}{\left(\frac{c_{\mathrm{P}}}{\eta_{\text {prop }}} \frac{H_{\text {fuel }}}{g}(1-S)+\frac{S}{\eta_{\text {elec }} \eta_{\text {prop }}}\right)} \frac{C_{\mathrm{L}}}{C_{\mathrm{D}}} \frac{1}{W} \mathrm{~d} E$

It is assumed that the power split and angle of attack are kept constant throughout the cruise flight. Furthermore, for the range of flight speeds and altitudes of interest, the power-specific fuel consumption, propeller efficiency and the combined electric efficiency are considered constant. In case of a flight at constant airspeed, this results in a gradual climb. Note that this climb is less steep than for conventional aircraft. In the case of a full electric aircraft, it becomes a horizontal flight profile.

$R=\frac{1}{\left(\frac{c_{\mathrm{p}}}{\eta_{\text {prop }}} \frac{H_{\text {ful }}}{g}(1-S)+\frac{S}{\eta_{\text {elec }} \eta_{\text {prop }}}\right)} \frac{C_{\mathrm{L}}}{C_{\mathrm{D}}} \int_{E_{\text {frinal }}}^{E_{\text {start }}} \frac{1}{W} \mathrm{~d} E$

The weight term is left in the integral since it is a function of the energy. Both the battery weight and fuel weight can be expressed in terms of energy based on their respective energy densities.

$W=W_{\text {empty }}+W_{\text {payload }}+W_{\text {bat }}+W_{\text {fuel }}$

$W=\frac{E_{\text {bat }} H_{\text {fuel }}+E_{\text {fuel }} H_{\text {bat }}}{H_{\text {bat }} H_{\text {fuel }}} g+W_{\text {empty }}+W_{\text {payload }}$

Using the hybridization factor, the equation can be rewritten as a function of total energy.

$W=\frac{\psi H_{\text {fuel }}+(1-\psi) H_{\text {bat }}}{H_{\text {bat }} H_{\text {fuel }}} g E+W_{\text {empty }}+W_{\text {payload }}$

The energy densities, payload weight, empty weight and hybridization factor are constant. Hence, the final range equation can be derived by solving the integral.

$$
\begin{aligned}
R_{\text {hybrid }}= & \frac{\eta_{\text {prop }}}{g\left(c_{\mathrm{P}} \frac{H_{\text {fuel }}}{g}(1-S)+\frac{S}{\eta_{\text {elec }}}\right)} \frac{C_{\mathrm{L}}}{C_{\mathrm{D}}} \frac{H_{\text {bat }} H_{\text {fuel }}}{\left(\psi H_{\text {fuel }}+(1-\psi) H_{\text {bat }}\right)} \\
& \ln \left(\frac{\frac{\left(\psi H_{\text {fuel }}+(1-\psi) H_{\text {bat }}\right)}{H_{\text {bat }} H_{\text {fuel }}} g E_{\text {start }}+W_{\text {empty }}+W_{\text {payload }}}{W_{\text {empty }}+W_{\text {payload }}}\right)
\end{aligned}
$$




\section{References}

1. Chakraborty, I., Mavris, D.N., Emeneth, M., Schneegans, A.: An integrated approach to vehicle and subsystem sizing and analysis for novel subsystem architectures. Proc. Inst. Mech. Eng. Part G J. Aerosp. Eng. 230(3), 496-514 (2016)

2. Wheeler, P.W., Clare, J.C., Trentin, A., Bozhko, S.: An overview of the more electrical aircraft. Proc. Inst. Mech. Eng. Part G J. Aerosp. Eng. 227(4), 578-585 (2013)

3. Naayagi, R.T.: A review of more electric aircraft technology. In: International Conference on Energy Efficient Technologies for Sustainability, ICEETS, Nagercoil, India (2013)

4. Gandolfi, R., Pellegrini, L.F., de Oliveira Jr., S.: More electric aircraft analysis using exergy as a design comparison tool. In: 48th AIAA Aerospace Sciences Meeting Including the New Horizons Forum and Aerospace Exposition, Orlando (2010)

5. Moir, I., Seabridge, A.: Aircraft systems-mechanical, electrical and avionics subsystems integration. $3^{\text {rd }}$ edn. Wiley, Chichester, England (2008)

6. Girishkumar, G., McCloskey, B., Luntz, A.C., Swanson, S., Wilke, W.: Lithium-air battery: promise and challenges. J. Phys. Chem. Lett. 1(14), 2193-2203 (2010)

7. Wells, D.P.: NASA green flight challenge: conceptual design approaches and technologies to enable 200 passenger miles per gallon. In: 11th AIAA Aviat. Technol., Integr. and Operations Conference, Virginia Beach, Virginia (2011)

8. Riboldi, C.E.D., Gualdoni, F.: An integrated approach to the preliminary weight sizing of small electric aircraft. Aerosp. Sci. Technol. 58, 134-139 (2016)

9. Pornet, C., Gologan, C., Vratny, P.C., Seitz, A., Schmitz, O., Isikveren, A.T., Hornung, M.: Methodology for sizing and performance assessment of hybrid energy aircraft. J. Aircr. 52(1), 341-352 (2015)

10. Friedrich, C., Robertson, P.A.: Hybrid-electric propulsion for aircraft. J. Aircr. 52(1), 176-189 (2015)

11. Stückl, S., van Toor, J., Lobentanzer, H.: VOLTAIR, the allelectric propulsion concept platform-a vision for atmospheric friendly flight. In: 28th International Congress of the Aeronautical Sciences, Brisbane, Australia (2012)

12. Bradley, M.K., Droney, C.K.: Subsonic ultra green aircraft research: phase I final report. NASA NASA/CR-2011-216847 (2011)

13. Perullo, C., Mavris, D.: A review of hybrid-electric energy management and its inclusion in vehicle sizing. Aircr. Eng. Aerosp. Technol. Int. J. 86(6), 550-557 (2014)

14. Ang, A.: Integrated performance analysis of a parallel hybrid electric propulsion system applied on short-range aircraft. Master thesis, Delft University of Technology, Delft, The Netherlands (2016)

15. Felder, J.L., Kim, H.D., Brown, G.V.: Turboelectric distributed propulsion engine cycle analysis for hybrid-wing-body aircraft. In: 47th AIAA Aerosp. Sciences Meeting including the New Horizons Forum and Aerosp. Expos., Orlando (2009)

16. Kim, H.D.: Distributed propulsion vehicles. In: 27 th International Congress of the Aeronautical Sciences, Nice, France (2010)

17. Williamson, M.: Air Power: The rise of electric aircraft. Eng. Technol. 9(10), 77-79 (2014)

18. Marwa, M., Martin, S.M., Martos, B.C., Anderson, R.P.: Analytic and numeric forms for the performance of propeller-powered electric and hybrid aircraft. AIAA SciTech Forum, Grapevine (2017)

19. Traub, L.W.: Range and endurance estimates for battery-powered aircraft. J. Aircr. 48(2), 703-707 (2011)

20. Chau, K.T., Wong, Y.S.: Overview of power management in hybrid electric vehicles. Energy Convers. Manag. 43, 1953-1968 (2002)

21. Cagatay Bayindir, K., Gozukucuk, M.A., Teke, A.: A comprehensive overview of hybrid electric vehicle: powertrain configurations, powertrain control techniques and electronic control units. Energy Convers. Manag. 52(2), 1305-1313 (2012)

22. Hung, J.Y., Gonzales, L.F.: On parallel hybrid-electric propulsion system for unmanned aerial vehicles. Prog. Aerosp. Sci. 52(1), $1-17$ (2012)

23. Friedrich, C., Robertson, P.A.: Design of a hybrid-electric propulsion system for light aircraft. In: 14th AIAA Aviat. Technol., Integration, and Operations Conference, Atlanta, Georgia (2014)

24. Bradley, M.K., Droney, C.K.: Subsonic ultra green aircraft research phase II: $\mathrm{n}+4$ advanced concept development. NASA, CR-2012-217556 (2012)

25. Kraytsberg, A., Ein-Eli, Y.: Review on Li-Air batteries-opportunities, limitations and perspective. J. Power Sources 196(3), 886-893 (2011)

26. Rostek, P.: Hybrid electric propulsion-a Eur. initiative for technol. development. In: Electr. and Hybrid Aerosp. Technol. Symposium (E\&H ATS), Bremen, Nov 17 (2015)

27. Schiferl, R., Flory, A., Livoti, W.C., Umans, S.D.: High-temperature superconducting synchronous motors: economic issues for industrial applications. IEEE Trans. Ind. Appl. 44(5), 1376-1384 (2008)

28. Brown, G. V.: Weights and efficiencies of electric components of a turboelectric aircraft propulsion system. In: 49th AIAA Aerosp. Sciences Meeting including the New Horizons Forum and Aerosp. Exposition, Orlando (2011)

29. Ashcraft, S.W., Padron, A.S., Pascioni, K.A., Stout, Jr., G.W.: Review of propulsion technologies for $\mathrm{N}+3$ subsonic vehicle concepts. NASA TM-2011-217239 (2011)

30. Masson, P.J., Luongo, C.A.: High power density superconducting motor for all-electric aircraft propulsion. IEEE Trans. Appl. Supercond. 15(2), 2226-2229 (2005)

31. Anonymous.: Medium voltage power cables. Synergy Cables Ltd. http://www.synergycables.com/index.php?show=484\&show type $=$ attachment $\&$ focused $=1$ (2017). Accessed 30 Oct 2017

32. Elmendorp, R., Vos, R., La Rocca, G.: A conceptual design and analysis method for conventional and unconventional airplanes. In: 29th Congress of the International Council of the Aeronautical Sciences, St. Petersburg, Russia (2014)

33. Raymer, D.P.: Aircraft design, a conceptual approach. $5^{\text {th }}$ edn. AIAA Education Series, Washington, DC (2012)

34. Roskam, J.: Airplane design part II: preliminary configuration design and integration of the propulsion system. $5^{\text {th }}$ edn. Design, Analysis and Research Corporation, Lawrence, Kansas (2017)

35. Torenbeek, E.: Advanced aircraft design. Wiley, New York (2013)

36. Isikveren, A.T., Kaiser, S., Pornet, C., Vratny, P.C.: Pre-design strategies and sizing techniques for dual-energy aircraft. Aircr. Eng. Aerosp. Technol. Int. J. 86(6), 525-542 (2014) 